\title{
AVALIAÇÃO RUMINAL E HEMOGASOMÉTRICA DE VACAS CLAUDICANTES DA RAÇA HOLANDÊS
}

\author{
BARBOSA, Antônio Amaral ${ }^{1}$; \\ GARCIA, Carla Augusta Sassi da Costa ${ }^{1}$; \\ CORRÊA, Marcio Nunes ${ }^{1}$; \\ FRANCK, Jorge Silva ${ }^{1}$; \\ ARAÚJO, Maria Carolina Narval ${ }^{1}$; \\ NOSCHANG, Joana Piagetti ${ }^{1}$; \\ SCHMITT, Eduardo ${ }^{1}$.
}

${ }^{1}$ Faculdade de Veterinária, Universidade Federal de Pelotas, Pelotas, RS - Brasil.

\section{RESUMO}

$\mathrm{O}$ objetivo deste estudo foi avaliar o pH ruminal e marcadores hemogasométricos de vacas claudicantes da raça Holandês. Foram utilizadas oito vacas multíparas, com produção média de 25,19 $\pm 4,92$ L/dia, com $67 \pm 6$ dias em lactação e contagem de células somáticas $<150.000$ células $/ \mathrm{mL}$. Os animais foram divididos em dois grupos conforme a avaliação do escore de locomoção (EL): Controle (vacas saudáveis, $n=4$ ) e Claudicantes (animais com EL acima de 2, n=4). A partir do diagnóstico de claudicação, foram realizadas coletas de líquido ruminal para avaliação do $\mathrm{pH}$ ruminal e de sangue para análises de $\mathrm{pH}$, bicarbonato, excesso de base e cálcio ionizado. As vacas do grupo Claudicantes apresentaram menor $\mathrm{pH}$ ruminal $(p=0,002)$ do que as vacas do grupo Controle, caracterizando um quadro de acidose ruminal. Além disso, os animais claudicantes apresentaram alcalose metabólica, demonstrada pelo maior $\mathrm{pH}$ sanguíneo $(p=0,01)$ e pressão de base $(p=0,007)$. Conclui-se que as vacas claudicantes apresentaram acidose ruminal e alcalose metabólica compensatória. O desequilíbrio ácido-básico foi responsável pelas alterações no perfil hemogasométrico e possivelmente pelas afecções podais encontradas.

Palavras-chave: Casco. Sistema locomotor. Acidose ruminal. 
Alterações do sistema locomotor em bovinos leiteiros vêm sendo associadas a baixos índices produtivos, acarretando perdas econômicas significativas, as quais podem atingir a produção de leite em até $50 \%$, além de interferir nas taxas reprodutivas e de mastite, configurando-se, então, como o problema mais oneroso aos sistemas leiteiros (FREITAS, 2011; GREENOUGH, 2007; WARNICK et al., 2001). As doenças podais são patologias que prejudicam os membros dos animais, provocando desconforto e podendo levar o animal a óbito em casos graves (MOTA; MELOTTI, 2017). Tais perdas podem ser reduzidas se for possível reconhecer a tempo (BRUIJNIS et al., 2009) e monitorar a evolução das alterações nas respostas adaptativas do casco, ou conseguir-se antecipar e identificar o desenvolvimento de condições patológicas associadas a problemas ortopédicos. Como alternativa, o desencadeamento inicial do processo patológico ligado à estrutura digital em bovinos, pode ser diagnosticado precocemente através da análise de marcadores biológicos e exames complementares, relacionados com afecções podais, como descrito por Knott et al. (2007), através de estudos realizados em equinos.

A síndrome da acidose lática bovina está associada a grandes aumentos de ácido lático no rúmen, resultante de dietas ricas em carboidratos, forragem de baixa fibra ou ambos. 0 impacto sistêmico da acidose pode ter múltiplas implicações fisiológicas, incluindo inflamação asséptica difusa das lâminas digitais (laminite) causando severos sinais álgicos nesses animais.

A laminite é responsável por $70 \%$ a $80 \%$ de todos os casos de claudicação em bovinos (AMETAJ et al., 2010; BARBOSA et al., 2016; NAGARAJA; LECHTENBERG, 2007) e sua ligação com a acidose parece estar associada a uma hipoperfusão persistente, que resulta em isquemia no dígito, sendo a gestão da acidose considerada, então, um ponto crítico na prevenção da laminite. A destruição da membrana basal por enzimas ativadas e toxinas bacterianas é outra teoria descrita para o desencadeamento da laminite, onde todas as perdas que surgem ao nível das interdigitações laminares ocorrem devido à chegada de toxinas por via hemática. Pollitt e Davies (1998) defendem que a hipoperfusão pode ser responsável pelo desenvolvimento da laminite, não sendo, portanto, uma consequência da doença. No entanto, a falha na perfusão das lâminas pode tornar-se benéfica se a doença for consequência da chegada de toxinas por via hemática (POLLITT; DAVIES, 1998). 
A alta produção dos rebanhos leiteiros impõe um desafio contínuo aos animais, exigindo que eles maximizem o consumo e a utilização de energia, o que favorece o aparecimento de distúrbios metabólicos, principalmente a acidose ruminal e a laminite. Levando em consideração que a acidose é a principal causa da laminite e o desequilíbrio ácido-básico pode ter consequências negativas ao sistema podal, nos últimos anos, ampliou-se o entendimento dos mecanismos fisiopatológicos envolvidos na patogênese dos transtornos dos dígitos dos bovinos, especialmente sobre a laminite (MÜLLING et al., 1999). Sua relação com as demais enfermidades e com o bem-estar animal, tem sido intensamente estudada (RODRIGUES et al., 2013), fazendo com que esta possível correlação necessite ser mais bem compreendida, principalmente através de métodos complementares de diagnóstico. Assim, este estudo teve por objetivo avaliar o $\mathrm{pH}$ ruminal e a hemogasometria de vacas claudicantes da raça Holandês.

O trabalho foi conduzido no Município de Capão do Leão (RS), Brasil, e todos os procedimentos realizados foram aprovados pelo Comitê de Ética em Experimentação Animal da Universidade Federal de Pelotas (CEEA/UFPEL 23110).

Foram utilizadas oito vacas da raça Holandês, ordenhadas duas vezes ao dia, multíparas, equilibradas quanto à produção de leite $(25,19 \pm 4,92 \mathrm{~L} / \mathrm{dia})$, dias em lactação (DEL: $67 \pm 6)$ e contagem de células somáticas (CCS: $<150.000$ células $/ \mathrm{mL}$ ). Os animais eram mantidos em um sistema Freestall, alimentados com Ração Total Misturada (RTM) à base de silagem de milho, polpa cítrica, milho, soja e núcleo mineral e vitamínico, disponibilizado aos animais duas vezes ao dia (manhã e tarde).

Os animais foram separados em dois grupos, após a avaliação do escore de locomoção (EL), seguindo a metodologia de Ferreira (2003), sendo o grupo Controle composto por 4 animais sadios e o grupo Claudicantes também por 4 animais. No grupo Claudicante todos os animais apresentaram EL acima de 2, sendo a erosão do talão a doença digital diagnosticada em todos os casos.

Para avaliação do $\mathrm{pH}$ ruminal foram coletados $30 \mathrm{~mL}$ de líquido ruminal, três horas antes da alimentação, através de bomba vácuo de dupla via adaptada para bovinos, a cada três dias durante 10 dias, desprezando os primeiros jatos para diminuir a contaminação com saliva. 0 
pH foi avaliado através de medidor de bancada portátil.

A análise hemogasométrica foi efetuada a cada três dias durante 15 dias, sendo determinada a partir da coleta de sangue venoso por punção da jugular, utilizando o equipamento i-STAT $\left(\right.$ Abbot $\left.^{\circledR}\right)$ dotado do cartucho CG8+. Dessa forma, foram analisados cálcio ionizado (iCa), pH sanguíneo, excesso de base (BE) e bicarbonato de sódio $\left(\mathrm{HCO}_{3}\right)$.

Os resultados foram analisados através do método MIXED MODEL, considerando como efeitos fixos o grupo (presença de claudicação) e o dia de coleta, bem como as interações entre essas variáveis. Os valores de $p$ foram considerados significativos quando menores que 0,05 .

Constatou-se que as vacas claudicantes apresentaram menor $\mathrm{pH}$ ruminal $(p=0,002)$ quando comparadas com as vacas sadias, caracterizando assim um quadro de acidose ruminal nos animais que apresentaram dificuldade de locomoção (Figura 1). Por outro lado, o mesmo grupo apresentou maior $\mathrm{pH}$ sanguíneo quando comparado com o grupo Controle $(p=0,01$; Figura 2), evidenciando um quadro de alcalose metabólica. Acredita-se que essa elevação tenha ocorrido como efeito compensatório da acidose ruminal, uma vez que também foi determinado índice mais elevado de pressão de base (BE; $p=0,007$, Figura 3a), substância alcalinizante, justificando assim a elevação do pH sanguíneo. Os valores de bicarbonato (HCO3; $p=0,06$, Figura $3 b$ ) sanguíneo apresentaram-se aumentados, apesar de não terem sido considerados significativos. Assim como observou-se menores índices de iCa ( $p=0,09$; Figura 4) no sangue de animais claudicantes. O cálcio ionizado participa da regulação do equilíbrio acido-básico. Isso pode ser justificado pela forma com que esse íon é liberado na circulação, visto que o paratormônio, principal hormônio envolvido na retirada do cálcio do osso, tem maior sensibilidade ao pH sérico ácido (CAMPION et al., 2015). 


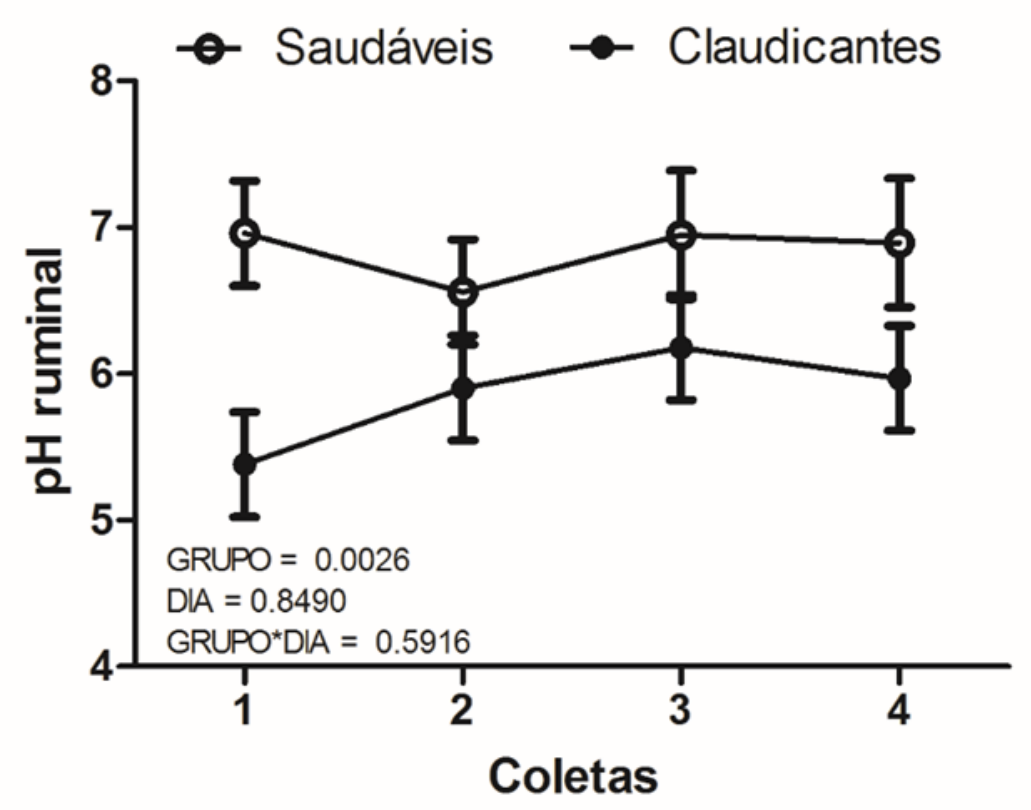

Figura 1 - pH ruminal de vacas claudicantes e saudáveis.

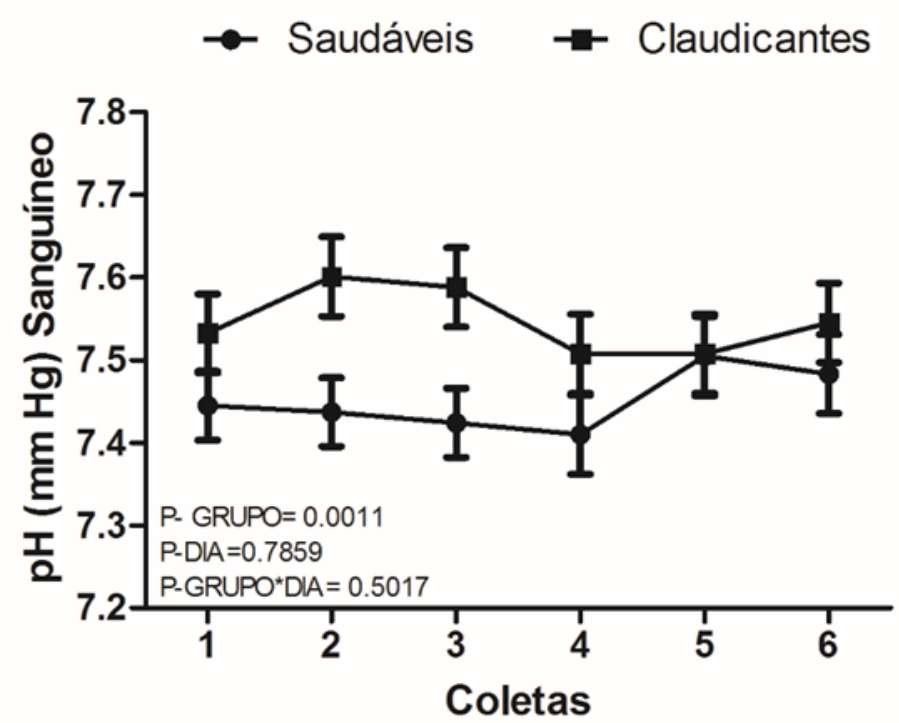

Figura 2 - pH sanguíneo de vacas claudicantes e saudáveis. 

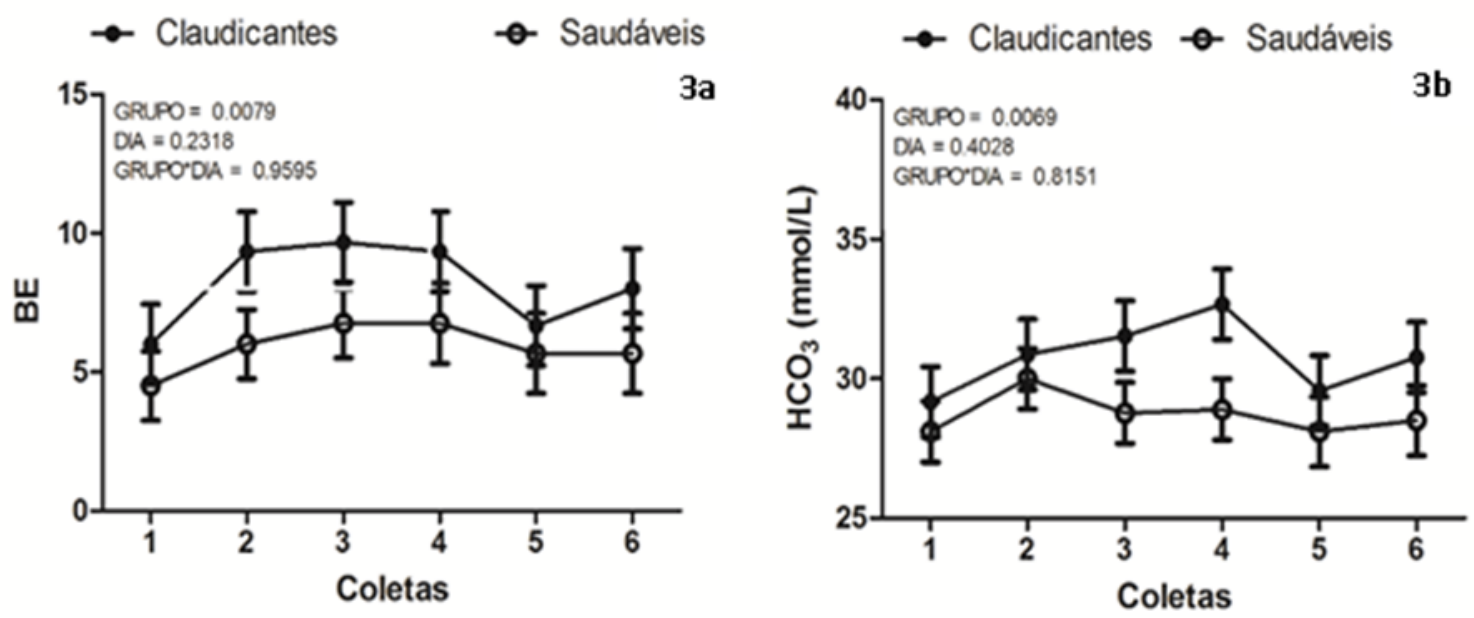

Figura 3a -Níveis sanguíneos de pressão de base (BE) de vacas saudáveis e claudicantes. Figura 3b - Níveis sanguíneos de bicarbonato $\left(\mathrm{HCO}_{3}\right)$ de vacas saudáveis e claudicantes.

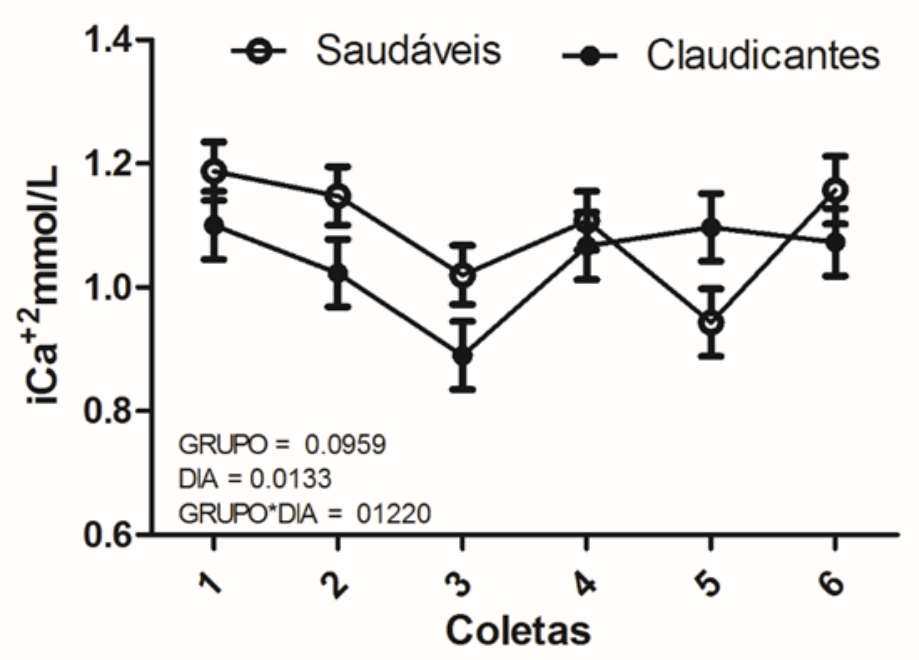

Figura 4 - Níveis séricos de cálcio ionizado (iCa) de vacas saudáveis e claudicantes.

Alguns distúrbios nutricionais, como a acidose ruminal, que causem uma diminuição do aporte de nutrientes ao casco, por alterações circulatórias ou alimentares, provocam uma diminuição da qualidade do estojo córneo, favorecendo o aparecimento de doenças, tanto metabólicas quanto podais, como a laminite (TÚLIO, 2006). A laminite está associada a diferentes graus de severidade da acidose ruminal, provocando uma alteração da hemodinâmica dos vasos capilares periféricos, ocasionando a liberação de substâncias 
vasoativas como a histamina, lactato e endotoxinas, resultando em vasoconstrição e dilatação, que lesionam os vasos capilares do cório gerando uma isquemia, diminuindo as concentrações de oxigênio e nutrientes nas extremidades das junções do cório, comprometendo a estrutura dos tecidos e causando a degradação física do casco, favorecendo a instalação de patógenos causadores das doenças podais (RADOSTITS et al., 2007). Entretanto, em casos de laminite aguda, observa-se aumento da pulsação nas veias digitais e seu ingurgitamento, não sendo compatível com vasoconstrição e isquemia. A explicação para a convergência destas duas situações está nas anastomoses arteriovenosas (AVAs) ou "shunts" arteriovenosos. As AVAs do cório se dilatam em resposta a vários estímulos como histamina, baixo $\mathrm{pH}$ do sangue, trauma ou estresse compressivo, resultando no aprisionamento do sangue. Deste modo, embora haja aumento do fluxo sanguíneo total para o dígito, uma vez que ele fica represado nas AVAs, ocorre diminuição da perfusão da microcirculação do cório, afetando as lâminas (OSSENT; LISCHER, 1998).

Segundo Kullmann et al. (2016), quando equinos apresentam hiperinsulinemia, a insulina em altas concentrações estimula fatores de crescimento, aumentando a adesão celular em detrimento de suas ações metabólicas, tornando-se assim um fator ativador do processo da laminite. Este processo resulta também em uma vasodilatação decorrente de hipertermia digital persistente, porém esse mecanismo não pode ser considerado o único fator envolvido na patogênese da doença em bovinos, visto que os resultados do presente estudo sugerem o envolvimento adicional de outros fatores, como ambiente ruminal e mecanismos compensatórios do equilíbrio ácido-básico, assim como também demonstrou DANSCHER et al. (2009), ao citar a relação importante entre acidose ruminal e laminite em bovinos.

Ainda não se conhece exatamente qual fator determina o aparecimento da inflamação no tecido lamelar, bem como a extensão dessa inflamação em outras estruturas do casco, tanto em bovinos (THOEFNER et al., 2005) quanto em equinos (LINFORD, 2006), outra espécie na qual a laminite tem grande importância clínica e econômica.

Em virtude das alterações vasculares reduzirem o aporte de nutrientes e oxigênio para a camada de células vivas da epiderme, as fases de proliferação e diferenciação das células epidermais ficam comprometidas, resultando em formação de estrato córneo macio e de baixa qualidade, que por consequência predispõe o animal a apresentar lesões associadas à 
laminite (SHEARER, 2017). Acredita-se que a acidose ruminal evidenciada no presente estudo, em vacas claudicantes, tenha contribuído para o agravamento ou aparecimento das afecções podais encontradas.

A alcalose metabólica caracteriza-se como um dos efeitos compensatórios da acidose ruminal, desencadeada pelo organismo na tentativa de alcançar a homeostase pelo equilíbrio ácido-básico através da liberação de álcalis na circulação. Essa compensação fisiológica foi comprovada neste trabalho, uma vez que vacas claudicantes que detinham $\mathrm{pH}$ ruminal menor, apresentaram elevação no pH sanguíneo quando comparadas com vacas saudáveis, sendo este aumento justificado pela elevação da pressão de base (BE) na circulação.

Em conclusão, as vacas claudicantes apresentaram acidose ruminal e alcalose metabólica compensatória. O desequilíbrio ácido-básico foi responsável pelas alterações no perfil hemogasométrico e possivelmente pelas afecções podais encontradas.

\section{RUMINAL AND HEMOGASOMETRIC EVALUATION OF CLAUDICANT HOLSTEIN COWS}

\section{ABSTRACT}

$\mathrm{T}$ his study aimed to evaluate the ruminal $\mathrm{pH}$ and hemogasometric markers of claudicating of the Holstein cows. Eight multiparous cows were used, with a mean production of $25.19 \pm 4.92 \mathrm{~L} /$ day and $67 \pm 6$ days in lactation and somatic cell count $<150,000$ cells $/ \mathrm{mL}$. The animals were divided into two groups according to the assessment of the locomotion score (LS): Control (healthy cows, $n=4$ ) and Claudicants (animals with LS above $2, n=4)$. From the diagnosis of claudication, ruminal fluid samples were collected to evaluate ruminal $\mathrm{pH}$ and blood for analysis of $\mathrm{pH}$, bicarbonate, baseline pressure, and ionized calcium. The cows in the Claudicants group had a lower ruminal $\mathrm{pH}(\mathrm{p}=0.002)$ than the cows in the Control group, characterizing a ruminal acidosis. Also, the claudicating animals showed metabolic alkalosis, demonstrated by the higher blood $\mathrm{pH}(\mathrm{p}=0.01)$ and base pressure $(p=0.007)$. It was concluded that the lameness cows presented ruminal acidosis and compensatory metabolic alkalosis. The acid-base imbalance was responsible for the alterations in the hemogasometric profile and possibly for the foot disorders found.

Keywords: Hoof. Locomotor system. Ruminal acidosis. 


\section{EVALUACIÓN RUMINAL Y HEMOGASOMÉTRICA DE VACAS CLAUDICANTES DE LA RAZA HOLSTEIN}

\section{RESUMEN}

E objetivo de este estudio fue evaluar el pH ruminal y marcadores hemogasométricos de vacas claudicantes de la raza Holstein. Se utilizaron ocho vacas multíparas, con una producción media de 25,19 \pm 4,92 L/día, con $67 \pm 6$ días en lactación y recuento de células somáticas $<150.000$ células $/ \mathrm{mL}$. Los animales fueron divididos en dos grupos según la evaluación de la puntuación del escore de locomoción (EL): Control (vacas sanas, $n=4$ ) y Claudicantes (con EL mayor a 2, n=4). A partir del diagnóstico de claudicación, se realizaron colectas de líquido ruminal para evaluación del pH ruminal y de sangre para análisis de $\mathrm{pH}$ sanguíneo, bicarbonato, exceso de base y calcio ionizado. Las vacas del grupo Claudicantes presentaran menor $\mathrm{pH}$ ruminal $(\mathrm{p}=0,002)$ que las vacas del grupo Control, caracterizando un cuadro de acidosis ruminal. Además, los animales claudicantes presentaron alcalosis metabólica, demostrada por el mayor $\mathrm{pH}$ sanguíneo $(p=0,01)$ y la presión de base $(p=0,007)$. Se concluye que las vacas claudicantes presentaran acidosis ruminal y alcalosis metabólica compensatoria. El desequilibrio ácido-base fue responsable por las alteraciones en el perfil hemogasométrico y posiblemente por los trastornos podales encontrados.

Palabras clave: Casco. Sistema locomotor. Acidosis ruminal.

\section{AGRADECIMENTOS}

O presente trabalho foi realizado com apoio do Conselho Nacional de Desenvolvimento Científico e Tecnológico (CNPq), Fundação de Amparo à Pesquisa do Estado do Rio Grande do Sul (FAPERGS) e da Coordenação de Aperfeiçoamento de Pessoal de Nível Superior -Brasil (CAPES) - Código de Financiamento 001.

\section{REFERÊNCIAS}

AMETAJ, B. N.; ZEBELI, Q.; IQBAL, S. Nutrition, microbiota, and endotoxin-related disease in dairy cows. Revista Brasileira de Zootecnia, v. 39, supl. especial, p. 433-444, 2010.

BARBOSA, A. A.; FERREIRA, C. M.; CORRÊA, M. N.; SCHWEGLER, E.; RAIMONDO, R. F.; DEL PINO, F. A. B. Lesões associadas à laminite subclínica e exame radiográfico digital em vacas 
da raça Holandês no período transicional. Ciência Animal Brasileira, v. 17, n. 4, p. 557-563, 2016.

BRUIJNIS, M. R. N.; HOGEVEEN, H.; STASSEN, E. N. Assessing economic consequences of foot disorders in dairy cattle using a dynamic stochastic simulation model. Journal Dairy Science, v. 93, n. 6, p. 2419-2432, 2009.

CAMPION, K. L.; MCCORMICK, W. D.; WARWICKER, J.; et al. Pathophysiologic Changes in Extracellular pH Modulate Parathyroid Calcium-Sensing Receptor Activity and Secretion via a Histidine-Independent Mechanism. Journal of the American Society of Nephrology, v. 26, n. 9, p. 2163-2171, 2015.

DANSCHER, A.M.; ENEMARK, J.M.D.; TELEZHENKO, E.; et al. Oligofrutose overloads induces lameness in cattle. Journal of Dairy Science, v. 92, n. 2, p. 607-616, 2009.

FERREIRA, P. M. Enfermidades podais em rebanho leiteiro confinado. Belo Horizonte: UFMG, 2003. 79p. Tese (Doutorado em Ciência Animal), Escola de Veterinária, Universidade Federal de Minas Gerais, 2003.

FREITAS, A. I. A. Pododermatite no Gado de Leite - Revisão de Literatura. PUBVET, v. 5, n. 30, p. 1192-1198, 2011.

GREENOUGH, P. R. Bovine Laminitis and Lameness: a Hands on Approach. St. Louis: Saunders Elsevier, 2007. 311p.

KNOTT, L.; TARLTON, J. F.; CRAFT, H.; WEBSTER, A. J. F. Effects of housing, parturition and diet change on the biochemistry and biomechanics of the support structures of the hoof of dairy heifers. The Veterinary Journal, v. 174, n. 2, p. 277-287, 2007.

KULLMANN, A.; WEBER, P. S.; BISHOP, J. B.; et al. Equine insulin receptor and insulin-like growth factor-1 receptor expression in digital lamellar tissue and insulin target tissues. Equine Veterinary Journal, v. 48, n. 5, p. 626-632, 2016.

LINFORD, R. L. Laminite (aguamento). In: SMITH, B. P. Medicina Interna de Grandes Animais, 3. ed. São Paulo: Manole e Barueri, 2006. P. 1116-1124.

MOTA, F. V; MELOTTI, V. D. Podologia Bovina. In: SIMPÓSIO DE TRABALHOS DE CONCLUSÃO DE CURSO E SEMINÁRIO DE INICIAÇÃO CIENTÍFICA, 12, 2017, Guará. ANAIS. Guará: ICESP, 2017. P. 2264-2270. Disponível em:

$<$ http://nippromove.hospedagemdesites.ws/anais_simposio/arquivos_up/documentos/artig os/cb64d2388a3b40b509f117cd22855a0a.pdf> .

MÜLLING, C. K.; BRAGULLA, H. H.; REESE, S.; BUDRAS, K. D.; STEINBERG, W. How structures in bovine hoof epidermis are influenced by nutritional factors. Anatomia Histologia Embryologia, v. 28, n. 2, p. 103-108, 1999. 
NAGARAJA, T. G.; LECHTENBERG, K. F. Liver abscesses in feedlot cattle. Veterinary Clinics of North America: Food Animal Practice, v. 23, n. 2, p. 351-369, 2007.

OSSENT, P.; LISCHER, C. J. Bovine laminitis: the lesions and their pathogenesis. In Practice, v. 20, n. 8, p. 415-427, 1998.

POLLITT, C. C.; DAVIES, C. T. Equine laminitis: its development coincides with increased sublamellar blood flow. Equine Veterinary Journal, v. 30, suppl. 26, 125-132, 1998.

RADOSTITS, O. M.; GAY, C. C.; HINCHCLIFF, K. W.; CONSTABLE, P. D. Veterinary Medicine: A textbook of the diseases of cattle, horses, sheep, pigs, and goats. 10. ed. Philadelphia: Saunders Elsevier, 2007. 2156p.

RODRIGUES, M.; DESCHK, M.; SANTOS, G. G. F.; PERRI, S. H. V.; MERENDA, V. R.; HUSSNI, C. A.; ALVES, A. L. G.; RODRIGUES, C. A. Avaliação das características do líquido ruminal, hemogasometria, atividade pedométrica e diagnóstico de laminite subclínica em vacas leiteiras. Pesquisa Veterinária Brasileira, v. 33, n. 1, p. 99-106, 2013.

SHEARER, J. K. Lameness in Cattle. Veterinary Clinics of North America: Food Animal Practice, v. 33, n. 2, p. i, 2017.

THOEFNER, M. B.; WATTLE, O.; POLLITT, C. C.; FRENCH, K. R.; NIELSEN, S. S. Histopathology of oligofructose-induced acute laminitis in heifers. Journal of Dairy of Science, v. 88, n. 8, p. 2774-2782, 2005.

TÚLIO, L. M. Estudo biométrico do casco bovino e bubalino: avaliação de características anatomo-fisiológicas do casco sadio. Curitiba: Gráfica da UFPR, 2006. 96p.

WARNICK, L. D.; JANSSEN, D.; GUARD, C. L.; GRÖHN, Y. T. The effect of lameness on milk production in dairy cows. Journal Dairy Science, v. 84, n. 9, p. 1988-1997, 2001.

Autor para correspondência: Antônio Amaral Barbosa. Campus Universitário Capão do Leão, S/N, Departamento de Clínicas Veterinárias, Faculdade de Veterinária, UFPEL, CEP 96160-000, Capão do Leão (RS). antoniobarbosa.vet@hotmail.com 